\title{
Prevalence of Post-Interview Communication in the Ophthalmology Match and Its Impact on Program Directors' Ranking of Applicants
}

\author{
David Cui, BA ${ }^{1}$ Nicholas L. Behunin, MD² Ingrid U. Scott, MD, MPH ${ }^{3}$ Heidi Luise Wingert ${ }^{4}$
}

${ }^{1}$ Penn State College of Medicine, Hershey, Pennsylvania

2 St. George Eye Center, St. George, Utah

${ }^{3}$ Departments of Ophthalmology and Public Health Sciences, Penn

State College of Medicine, Hershey, Pennsylvania

${ }^{4}$ University of Florida Honors Program, Gainesville, Florida

\begin{abstract}
Address for correspondence Ingrid U. Scott, MD, MPH, Departments of Ophthalmology and Public Health Sciences, Penn State College of Medicine, 500 University Dr, HU19, Hershey, PA 17033-0850

(e-mail: iscott@pennstatehealth.psu.edu).
\end{abstract}

\begin{abstract}
Keywords

- residency

- post-interview communication

- survey

- San Francisco Match

- match

- interview

- medical student

- prevalence

- impact

- mentor

- faculty mentor

Objective The aim of this study is to investigate the prevalence of post-interview communication (PIC) during the ophthalmology residency match process and its impact on program directors' (PD's) ranking of applicants.

Design Prospective cross-sectional survey.

Methods An anonymous, online survey was emailed to the PD of each ophthalmology residency program accredited by the Accreditation Council for Graduate Medical Education.

Results Fifty-four percent (63/116) of PDs completed the survey. Eighty-five percent (54/63) of PDs received PIC from applicants or applicants' faculty mentors during the 2018 to 2019 application cycle; $62 \%$ (39/63) received PIC regarding $>25 \%$ of applicants interviewed. Although 41\% (26/63) of PDs reported they would likely rank an applicant higher due to PIC endorsement from a faculty mentor known to the PD, only $3 \%(2 / 63)$ believed that applicants who did not have a faculty mentor conduct PIC on their behalf were disadvantaged. Fourteen percent (9/63) of PDs reported they would likely rank an applicant higher due to PIC endorsement from a faculty mentor unknown to the PD, and $3 \%(2 / 63)$ reported they would likely rank an applicant higher as a result of PIC from the applicant.

Conclusion There is a high prevalence of PIC during the ophthalmology residency match process. The potential impact of PIC on PDs' ranking of applicants varies according to whether the PIC is from a faculty member known to the PD, a faculty member unknown to the PD, or the applicant. This may disadvantage applicants without faculty mentors known to PDs.
\end{abstract}

The Ophthalmology Residency Matching Program (OMP) coordinates the application and matching process for ophthalmology residency positions and for internship positions that are integrated with ophthalmology residency positions. ${ }^{1}$ The OMP was established by the Association of
University Professors of Ophthalmology and is administered by the San Francisco Match (SF Match). This program is separate from the National Residency Matching Program (NRMP), which coordinates the residency match for nearly all other medical specialties and for the ophthalmology received

January 17, 2020

accepted

April 22, 2020
DOI https://doi.org/

$10.1055 / \mathrm{s}-0040-1713364$. ISSN $2475-4757$.
Copyright $\odot 2020$ by Thieme Medical

Publishers, Inc., 333 Seventh Avenue, New York, NY 10001, USA. Tel: +1(212) 760-0888.
License terms

$(\circledast) \Theta \circledast$ 
residency postgraduate year 1 internship year positions for those students who are not part of an integrated internship/ ophthalmology residency program.,

Studies outside of ophthalmology have reported that post-interview communication (PIC) is highly prevalent, with up to $91 \%$ of applicants and up to $97 \%$ of program directors (PDs) for certain specialties receiving or sending PIC. ${ }^{3-6}$ Prior studies in and outside of ophthalmology have reported that PIC initiated by an applicant may have little to no impact on that applicant's rank list position. ${ }^{7-9}$ Both applicants and PDs report experiencing unethical behaviors or match violations during the course of sending or receiving PIC; applicants report feeling pressured to reveal their rank list, being asked to rank a program first to be ranked in return, being deliberately misled by their ranking, and being contacted by phone (a Urology Match violation), 3,5,10-12 whereas many PDs experienced dishonesty by applicants falsely stating they would rank the PD's program first. ${ }^{7,10}$

The NRMP and SF Match are brief and vague with respect to their match rules regarding PIC, with the NRMP's code of conduct only instructing programs to respect an applicant's privacy and confidentiality, and to refrain from coercive questions. ${ }^{13}$ The SF Match has similar rules; ophthalmology residency programs are to keep rank lists confidential and not request a conditional statement of intent from applicants. ${ }^{1}$ Aside from requiring that PIC include no explicit coercion on an applicant, both matching programs leave the specific contents of PIC to the discretion of individual applicants and residency programs. Applicants or programs may be tempted to engage in PIC with the aim of improving their respective rank list position, or may feel obligated to reply to PIC to not appear disinterested in the other party.

For ophthalmology-specific PIC, a study published in 2018 indicated that $75 \%$ of PDs prefer no PIC between programs and applicants, with $56 \%$ believing PIC to be unethical and unproductive. ${ }^{7}$ The study also suggests that PDs are wary of applicant-initiated PIC, with $72 \%$ having been misled by an applicant, and that applicant-initiated PIC has little if any impact on their ranking of applicants. ${ }^{7}$

To our knowledge, and based on a computerized literature search of the PubMed database, there is no published information on the prevalence of PIC in ophthalmology and the potential impact on applicant rank position of PIC initiated by faculty mentors of applicants. A survey of obstetrics and gynecology PDs reported that an applicant's faculty mentor, if known to the PD, can have a tremendous impact on improving the applicant's rank position compared with PIC initiated by the applicant themselves. ${ }^{14}$ The purpose of our study is to investigate the prevalence of PIC during the ophthalmology residency match process and its impact on PDs' ranking of applicants.

\section{Materials and Methods}

The study was approved by the Institutional Review Board of the Penn State College of Medicine and conducted in accordance with the Declaration of Helsinki. An email with the study description, an invitation to participate in the study, and a secure survey link was sent to the PD of each of the 116 ophthalmology residency programs accredited by the Accreditation Council for Graduate Medical Education on June 2019. Contact information for each PD was obtained using the public online database FREIDA by the American Medical Association. ${ }^{15}$ The survey (-Table 1) was constructed using the secure online application REDCap hosted at the Penn State College of Medicine. ${ }^{16}$ Responses were collected automatically and managed under a de-identified record number generated by REDCap. Non-responders were anonymously identified by the REDCap system and were sent two reminder emails each 2 to 3 weeks apart.

\section{Results}

Sixty-three of 116 (54\%) ophthalmology residency PDs completed the survey. The participating PDs served in their residency leadership position for an average of 8.7 years and interviewed an average of 49 candidates per year. Eightyfive percent (54/63) of PDs received PIC from either applicants or applicants' faculty mentors during the 2018 to 2019 application cycle, and 62\% (39/63) received PIC regarding over $25 \%$ of applicants interviewed.

- Table 2 shows PDs' perspectives regarding the impact of PIC on PDs' ranking of applicants by the type of PIC, the initiating party, and whether or not the faculty mentor was known by the surveyed PD. Forty-one percent (26/63) of PDs reported they would likely rank an applicant higher due to PIC endorsing the applicant as outstanding from a faculty mentor known to the PD, 14\% (9/63) reported they would rank an applicant higher due to PIC endorsing the applicant as outstanding from a faculty mentor unknown to the PD, and 3\% (2/63) reported they would rank an applicant higher as a result of PIC from the applicant stating the applicant intends to rank the PD's program highly. - Table 3 summarizes the PDs' attitudes toward the perceived fairness of PIC. A large majority of PDs believe applicants are not at a disadvantage if the applicants do not engage in PIC $(57 / 63,90 \%)$ or if the applicants do not have a faculty mentor advocate on their behalf via PIC (54/63, 86\%). Only 3\% (2/63) of PDs believed that applicants who did not have a faculty mentor conduct PIC on their behalf were disadvantaged. Ten (16\%) PDs believed PIC initiated by an applicant or faculty mentor is fair/appropriate, 27 (43\%) disagreed with this statement, and $26(41 \%)$ neither agreed nor disagreed.

\section{Discussion}

Consistent with published studies in other specialties, ${ }^{4-6}$ our study results indicate a high prevalence of PIC during the ophthalmology match process, with $85 \%$ of surveyed PDs having received PIC from either applicants or applicants' faculty mentors during the 2018 to 2019 application cycle, and $62 \%$ having received PIC regarding over $25 \%$ of their interviewed applicants. One potential explanation for the high prevalence of PIC received by ophthalmology PDs is that ophthalmology is a competitive specialty; data from the 2018 match show that, among senior medical student 
Table 1 Survey questionnaire distributed to Ophthalmology Residency Program Directors

\begin{tabular}{|c|}
\hline 1. How many years have you been a Residency Program Director? \\
\hline 2. Approximately how many candidates does your program interview each year? \\
\hline $\begin{array}{l}\text { 3. During the } 2018-2019 \text { interview season, did you engage in post-interview communication with applicants or their faculty } \\
\text { mentor? }\end{array}$ \\
\hline $\begin{array}{l}\text { a. If yes, what is the estimated percentage of interviewed candidates who engaged in (sent or received) post-interview } \\
\text { communication? }\end{array}$ \\
\hline i. $1-25 \%$ \\
\hline ii. $26-50 \%$ \\
\hline iii. $51-75 \%$ \\
\hline iv. $76-100 \%$ \\
\hline $\begin{array}{l}\text { 4. During the } 2018-2019 \text { interview season, which of the following post-interview communications caused you (or would have } \\
\text { caused you) to rank a candidate more favorably on your list? (select all that apply) }\end{array}$ \\
\hline a. Candidate sent a thank you note \\
\hline b. Candidate stated they were "ranking your program highly/number 1 " \\
\hline $\begin{array}{l}\text { c. Candidate's faculty mentor, who you DO NOT know, contacted you stating the candidate was "ranking your program } \\
\text { highly/number } 1 \text { " }\end{array}$ \\
\hline $\begin{array}{l}\text { d. Candidate's faculty mentor, who you DO know, contacted you stating the candidate was "ranking your program } \\
\text { highly/number 1" }\end{array}$ \\
\hline e. Candidate's faculty mentor, who you DO NOT know, contacted you endorsing the candidate as outstanding \\
\hline f. Candidate's faculty mentor, who you DO know, contacted you endorsing the candidate as outstanding \\
\hline 5. What are your beliefs on the following statements? (Options: Disagree, Neither Agree nor Disagree, Agree) \\
\hline a. Candidates who did NOT contact you post-interview were disadvantaged compared with those who did \\
\hline b. Candidates who did NOT have a mentor contact you on their behalf were disadvantaged compared with those who did \\
\hline $\begin{array}{l}\text { c. It is fair/appropriate that post-interview communication by an applicant OR their faculty mentor may improve the } \\
\text { applicant's position on a rank list }\end{array}$ \\
\hline
\end{tabular}

Table 2 Ophthalmology program directors' perspectives on the impact of post-interview communication on their ranking of applicants $(n=63)$

\begin{tabular}{|l|c|}
\hline \multicolumn{1}{|c|}{ Type of post-interview communication } & Would likely rank the applicant higher \\
\hline Thank you note from candidate & $1(1.6 \%)$ \\
\hline Applicant stated they were ranking the program highly & $2(3.2 \%)$ \\
\hline $\begin{array}{l}\text { Faculty mentor, unknown to the program director, } \\
\text { stated the applicant was ranking a program highly }\end{array}$ & $46.3 \%)$ \\
\hline $\begin{array}{l}\text { Faculty mentor, known to the program director, } \\
\text { stated the applicant was ranking the program highly }\end{array}$ & $12(19.0 \%)$ \\
\hline $\begin{array}{l}\text { Faculty mentor, unknown to the program director, } \\
\text { endorsed the applicant as outstanding }\end{array}$ & $9(14.3 \%)$ \\
\hline $\begin{array}{l}\text { Faculty mentor, known to the program director, } \\
\text { endorsed the applicant as outstanding }\end{array}$ & $26(41.3 \%)$ \\
\hline
\end{tabular}

Table 3 Ophthalmology program directors' perspectives on the fairness of PIC $(n=63)$

\begin{tabular}{|l|l|l|l|}
\hline Statement & Disagree & Neither agree nor disagree & Agree \\
\hline Applicants who did not engage in PIC were disadvantaged & $57(90.5 \%)$ & $6(9.5 \%)$ & $0(0 \%)$ \\
\hline $\begin{array}{l}\text { Applicants who did not have a faculty mentor advocate } \\
\text { on their behalf via PIC were disadvantaged }\end{array}$ & $54(85.7 \%)$ & $7(11.1 \%)$ & $2(3.2 \%)$ \\
\hline PIC by an applicant or his/her faculty mentor is fair/appropriate & $27(42.9 \%)$ & $26(41.3 \%)$ & $10(15.9 \%)$ \\
\hline
\end{tabular}

Abbreviation: PIC, post-interview communication. 
applicants from US allopathic medical schools, the proportion who match in ophthalmology (86\%) is lower compared with the proportion who match in other specialties (92\%). ${ }^{17,18}$ In addition, those who matched in ophthalmology had a higher mean United States Medical Licensing Exam (USMLE) Step 1 score compared with those who matched in other specialties (245 vs. 233 , respectively). ${ }^{17,18}$ The competitive nature of the ophthalmology match may motivate applicants to pursue PIC as a means to try to improve their match success. Data on the prevalence of PIC received by PDs from other specialties is insufficient to determine whether or not the competitiveness of a specialty is associated with increased PIC prevalence.

A PIC endorsement from an applicant's faculty mentor known to the PD is much more likely to translate into the PD ranking that applicant higher on the rank list compared with a PIC endorsement from a faculty mentor not known to the PD or PIC from the applicant ( $41.3 \%$ vs. $14.3 \%$ vs. $3.2 \%$, respectively). These data suggest that applicants may benefit significantly if they have a well-known faculty member who is willing to provide endorsing PIC on the applicants' behalf, and that applicants without an endorsing faculty member known to the PD may be disadvantaged. The fact that $41 \%$ of the surveyed PDs reported they would likely rank an applicant higher if they received a PIC endorsing the applicant as outstanding from an applicant's faculty mentor known to the PD, yet only $3 \%$ of PDs believed that applicants without an endorsing faculty mentor conducting PIC on their behalf were disadvantaged suggests there is a disconnect between the actual versus PDs' perceived impact of PIC on PDs' ranking of applicants.

Only 10 (16\%) of the PDs surveyed believed PIC initiated by an applicant or faculty mentor with the potential to affect the ranking list is fair or appropriate. This is consistent with the results of a study by Chen et al, ${ }^{7}$ in which the majority (46/74, $62 \%$ ) of responding ophthalmology PDs believed that the Ophthalmology Matching Program should institute a policy of no PIC between applicants and faculty during the residency match period. The study by Chen et al investigated only PIC between PDs and applicants; PIC between PDs and applicants' faculty mentors was not studied. To our knowledge, the current study is the first to investigate the prevalence of PIC between PDs and applicants' faculty mentors, and the potential impact of such PIC on PDs' ranking of applicants. The finding in our study that PIC endorsement from a faculty mentor known to the PD is much more likely to affect the PD's ranking of the applicant compared with other forms of PIC suggests an uneven playing field among applicants based on whether or not applicants have faculty mentors who are known to PDs and who conduct endorsing PIC.

According to the 2018 NRMP Program Director Survey, letters of recommendation are one of the most important factors for considering an applicant for interview and deciding the applicant's rank list position. ${ }^{19}$ Given the findings of the current study, future areas of research include investigating whether the impact on the ranking of applicants varies according to whether or not the author of a letter of recommendation is known or unknown to the applicant ranker, is an ophthalmologist or in another field of medicine, and whether PIC from an endorsing faculty mentor has an additive impact on the ranking of applicants beyond a letter of recommendation. Additionally, a future area for research is to investigate whether the recent change in the USMLE Step 1 from a graded score to a pass/fail result ${ }^{20}$ will be associated with a change in the impact of PIC and faculty endorsements of applicants (either through letters of recommendation or PIC) on the ranking of applicants.

Limitations of the current study include potential response bias. PDs with a prior experience with PIC that strongly impacted their match results may have been more likely to participate. However, the response rate of $54 \%$ compares favorably with those achieved in recent ophthalmology PD surveys (33-64\%). ${ }^{7,21,22}$ Further, the relative impact on PDs' ranking of applicants of the various forms of PIC investigated in this study may not be identical to the impact of the various forms of PIC on the ranking of applicants by other individuals involved in the applicant rank list decision-making process. Finally, the current study did not investigate whether PIC from an endorsing faculty mentor has an additive impact on the ranking of applicants beyond a letter of recommendation.

In summary, there is a high prevalence of PIC during the ophthalmology residency match process. PIC endorsement from a faculty mentor known to the PD is much more likely to affect the PD's ranking of the applicant compared with other forms of PIC. This suggests an uneven playing field among applicants based on whether or not applicants have faculty mentors who are known to PDs and who conduct endorsing PIC.

\section{Conflict of Interest}

None declared.

\section{References}

1 San Francisco Match. Overview-Ophthalmology Residency Match. Available at: https://sfmatch.org/SpecialtyInsideAll.aspx?id=6\&typ $=2 \&$ name $=$ Ophthalmology. Accessed August 10, 2019

2 The National Resident Matching Program. About NRMP. Available at: http://www.nrmp.org/about-nrmp. Accessed August 10, 2019

3 Brooks JT, Reidler JS, Jain A, LaPorte DM, Sterling RS. Post-interview communication during application to orthopaedic surgery residency programs. J Bone Joint Surg Am 2016;98(19):e84

4 Farber NJ, Neylan CJ, Srivastava A, et al. The urology match process and the limited value of post-interview communication for program directors. Urology 2019;128:23-30

5 Jena AB, Arora VM, Hauer KE, et al. The prevalence and nature of postinterview communications between residency programs and applicants during the match. Acad Med 2012;87(10):1434-1442

6 Berriochoa C, Reddy CA, Dorsey S, et al. The residency match: interview experiences, postinterview communication, and associated distress. J Grad Med Educ 2018;10(04):403-408

7 Chen AJ, Tran EM, Clark MA, Scott IU, Greenberg PB. Preferences and practices of U.S. ophthalmology residency program directors regarding post-interview communication with residency applicants. J Acad Ophthalmol 2018;10(01):43-47

8 Swan EC, Baudendistel TE. Relationship between postinterview correspondence from residency program applicants and subsequent applicant match outcomes. J Grad Med Educ 2014;6(03): 478-483 
9 Grimm LJ, Avery CS, Maxfield CM. Residency postinterview communications: more harm than good? J Grad Med Educ 2016;8(01):7-9

10 Teichman JM, Anderson KD, Dorough MM, Stein CR, Optenberg SA, Thompson IM. The urology residency matching program in practice. J Urol 2000;163(06):1878-1887

11 American Urological Association. Urology and Specialty Matches. Available at: https://www.auanet.org/education/ auauniversity/for-residents/urology-and-specialty-matches. Accessed August 10, 2019

12 Farber NJ, Neylan CJ, Kaplan A, Singer EA, Elsamra SE. The urology match and postinterview communication. Urology 2018;122:44-51

13 The National Resident and Matching Program. Match Communication Code of Conduct. Available at: http://www.nrmp.org/communication-code-of-conduct. Accessed August 10, 2019

14 Frishman GN, Matteson KA, Bienstock JL, et al. Postinterview communication with residency applicants: a call for clarity!. Am J Obstet Gynecol 2014;211(04):344-350.e1

15 The American Medical Association. The AMA Residency \& Fellowship Database. Available at: https://freida.ama-assn.org/Freida. Accessed August 10, 2019

16 Harris PA, Taylor R, Thielke R, Payne J, Gonzalez N, Conde JG. Research electronic data capture (REDCap)-a metadata-driven methodology and workflow process for providing translational research informatics support. J Biomed Inform 2009;42(02): 377-381

17 The National Residency and Matching Program. Charting Outcomes in the Match: U.S. Allopathic Seniors. Available at: https:// www.nrmp.org/wp-content/uploads/2018/06/Charting-Outcomes-in-the-Match-2018-Seniors.pdf. Accessed August 10, 2019

18 The San Francisco Match and the Association of University Professors of Ophthalmology. Ophthalmology Residency Match Summary Report 2018. Available at: https://www.sfmatch.org/ PDFFilesDisplay/Ophthalmology_Residency_Stats_2018.pdf. Accessed August 10, 2019

19 The National Resident and Matching Program. Results of the 2018 NRMP Program Director Survey. Available at: https://www. nrmp.org/wp-content/uploads/2018/07/NRMP-2018-ProgramDirector-Survey-for-WWW.pdf. Accessed August 10, 2019

20 United States Medical Licensing Examination. USMLE Score Reporting FAQs. Available at: http://usmle.org/usmlescoring/ faq.html. Accessed August 10, 2019

21 Chen AJ, Chan JJ, Scott IU, Greenberg PB. Ophthalmic resident education on preventable surgical errors. JAMA Ophthalmol 2013;131(09):1238-1240

22 Coombs PG, Feldman BH, Lauer AK, Paul Chan RV, Sun G. Global health training in ophthalmology residency programs. J Surg Educ 2015;72(04):e52-e59 